\title{
Protective Effect of Rasayana Herbs on Lead Acetate-induced Testicular Toxicity in Wistar Rats
}

\author{
Vikas Sharma, Nagendra S Chauhan, Umesh K Patil, Vinod Kumar Dixit*
}

Department of Pharmaceutical Sciences, Dr. Harisingh Gour Vishwavidyalaya, Sagar, Madhya Pradesh, INDIA.

\begin{abstract}
In recent years, the use of the herbs in reducing heavy metal toxicities has increased worldwide. Rasayana drugs have been reported to have improved reproductive activity. In this study, we investigated the protective effects of Anacyclus pyrethrum, Spilanthes acmella and Pedalium murex on lead acetate-induced testicular damage in rats. The sample used 30 male rats divided into 5 groups: negative control (rats were given daily with $1 \%$ sodium CMC solution were given daily with lead acetate in mineral water at $250 \mathrm{mg} / \mathrm{l}(1 \mathrm{ml}$ mineral water poisoned); positive control (rats /day/ rat) orally once in a day for 90 days); and the treatment group (rats were given the Anacyclus pyrethrum $150 \mathrm{mg} / \mathrm{kg}$, Spilanthes acmella $150 \mathrm{mg} / \mathrm{kg}$ and Pedalium murex $150 \mathrm{mg} / \mathrm{kg}$ BW orally once in day for 90 days. After 90 days testicular tissue and sperm count, motility and viability in the epididymis were measured in rats. Testis samples were also collected for histopathological studies. Results showed that Lead acetate decreased the sperm count, motility, viability and altered histopathological testis compared to the negative control. However, administration of Rasayana drugs significantly improved the histopathological in testis, increased the sperm count, motility, viability and also significantly increased the testosterone level in drug treated rats. From the results of this study we concluded that the Rasayana drugs could be a potent natural product provides a promising protective effect against lead acetate induced testicular toxicity in rats.

Key words: Vajikaran, Rasayana, Lead acetate, Anacyclus pyrethrum, Spilanthes acmella, Pedalium murex
\end{abstract}

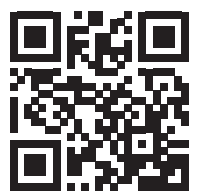

www.ijnponline.com

DOI : 10.5530/ijnp.2021.1.3

\section{INTRODUCTION}

In recent years, there has been an increasing interest in the contribution of occupational and environmental exposures to toxic pollutants to declining sperm concentration and human male infertility. There are epidemiological confirming evidences that exposure to industrial metal aerosols may be detrimental to male reproduction system. Heavy metals produce cellular impairments at structural and functional level in male reproductive system. ${ }^{[1]}$ The effect of heavy metals, such as lead, mercury, cadmium, chromium and arsenic on male reproduction system has been studied in details in various experimental species. One of the first materials to be demonstrated as detrimental to fertility was lead. Lead appears in homes in many forms as lead piping, lead-containing solders, paints, ceramic glazes, pewter and base metal utensils and fixtures. Also, cream powder, lipstick and hair color have lead. Agricultural soil contamination may be responsible for lead found in many herbal medicines and cigarettes. ${ }^{[2]}$

The role of lead in male sub-fertility factor is of particular current interest. In men, especially in professional workers, lead exposure results in infertility and sterility, testicular atrophy, cellular degeneration and reductions in seminiferous tubule diameter (STD) and sperm count, depending on the dose and time of exposure. ${ }^{[3]}$ In animal models, lead exposure consistently decreases male reproductive function at the level of the hypothalamic-pituitary-testicular axis. The effects of lead on adult rat testis have been widely studied and observations demonstrate that lead in particular alters those organs, as evidenced by testicular necrosis and atrophy in rodents. ${ }^{[4]}$ However, the effects of chemical agents on fertility and development may consider the fact that exposure to some materials during critical period of development may affect the adult life and even generations to come. In humans and experimental animals the gastrointestinal absorption of lead after chronic exposure also exerts a wide number of adverse biological effects during lactation, more so than in adult life, since neonates absorb 40-50 times more lead than adults. It appears from the evidences that the neonatal period is a critical stage in the process of sexual development and maturation in primates. Interferences with normal brain pituitary gonadal function during this period appear to impact adversely on subsequent reproductive function. Given the recent evidence that the reproductive potential of the human male has declined rather dramatically over the last 50 years and that clinical conditions associated with abnormal testicular function are on the rise, continued investigation in this area would appear to be imperative. ${ }^{[5]}$

A special class of Rasayana drugs is known as Vrishya or Vajikarana. They are associated with an improvement of male sexual potency and thereby ensure a supraja, or better progeny. Traditionally, the main aim of using Vajikaran was to achieve successful copulation for healthy reproduction, along with an improvement in sexual pleasure as an additional benefit. Besides having many specific drugs for enhancing sexual functions, the most commonly used are Akarkara and Gokharu. ${ }^{[6]}$

Therefore, there is a need to work upon measures that could in some way help in restoring the damage that the testis may incur in due course of time. The prevention of lead induced testicular damage and restoration 
of reproductive functions in patients is an issue that needs scientific attention. The lead for ameliorative substance can be taken from synthesis as well as natural sources. The herbs Anacyclus pyrethrum (A.pyrethrum), Spilanthes acmella (S. acmella) and Pedalium murex (P. murex) have been advocated for improving reproductive functions in male. With this aspect in mind the ethanolic extract of the herbs under investigation were tested for their effectiveness against lead acetate induced damage on testicular function. It was also envisaged to determine whether the herbs could assist in reversing the infertility caused by lead acetate.

In our previous studied $A$. pyrethrum, S. acmella, $P$. murex extracts show the maximum effects in dose of $150 \mathrm{mg} / \mathrm{kg}$ b.w after 28 days treatment. ${ }^{[7-10]}$ This maximum effective dose $(150 \mathrm{mg} / \mathrm{kg})$ was thus used for further experiments.

\section{MATERIALS AND METHODS}

\section{Animal stock}

The protocol for experimentation was approved by Institutional Animal Ethics Committee of Dr. Hari Singh Gour University, Sagar, India (Animal Eths Comm/IE/98/Reg No379/01/ab/CPCSEA) and was in accordance with international standard on the care and use of experimental animals. Inbred, 30 male rats 10-12 months old and weighed 250-300 g was used. The rats were housed at room temperature $\left(24 \pm 2^{\circ} \mathrm{C}\right.$ ) on a reversed day-night cycle (dark from 06:00 to 18:00) and relative humidity of $50-55 \%$. They were fed with a standard pellet diet and water ad libitum.

\section{Preparation of extracts}

The flowers of the Spilanthes acmella and fruits of Pedalium murex plant were collected from the area in vicinity of the campus and were dried at room temperature $\left(25-35^{\circ} \mathrm{C}\right)$. The plant Spilanthes acmella (L.) Murr. and Pedalium murex Linn. was identified and authenticated at Department of Botany, Dr. H. S. Gour University Sagar (M.P.) The roots of Anacyclus pyrethrum DC. Were procured from the market and authenticated by Agharkar Research Institute, Pune (Authentication no. Auth. 07-86). Next, the plant materials were reduced to powder and passed through a sieve (60 mesh), fed in a soxhlet extractor and extracted with ethanol (95\%) till complete exhaustion. The extract was collected and dried under vacuum by using a rota vapor (Heidolph, Germany).

A. pyrethrum ethanolic extract was dark brown colored and semisolid in consistency (yield $7.2 \% \mathrm{w} / \mathrm{w}$ ). Ethanolic extract of $S$. acmella was greenish brown and semisolid with a yield of $6.1 \% \mathrm{w} / \mathrm{w}$. P. murex ethanolic extract was brown colored, semisolid with a characteristic odor (yield 5.2\% $\mathrm{w} / \mathrm{w})$. Before oral administration, all extracts was suspended in $1 \%$ sodium CMC.

\section{Treatment}

The male rats 10-12 months old and weighed 250-300 g was used for present study. The animals were divided into six groups of six rats each. Group I (Control) animals served as the control and received only vehicle $1 \mathrm{ml}$ of $1 \%$ sodium CMC solution. Group II (LA) Groups III $(\mathrm{LA}+\mathrm{AP} 150), \mathrm{IV}(\mathrm{LA}+\mathrm{SP} 150)$ and V (LA + PM 150) were given ethanolic extracts of A. pyrethrum, S. acmella and P. murex respectively, with dose of $150 \mathrm{mg} / \mathrm{kg}$ b.w. for 90 days. The present study protocol was pursued. ${ }^{[11,12]}$

\section{Functional studies}

\section{Effect on body weight and weight of sexual organs}

After 28 days of treatment as described above, all the treated and control animals were weighed and the body weights were recorded. Animals were sacrificed by decapitation and the sexual organs (testis, seminal vesicles, epididymis and prostate glands) were dissected out carefully and weighed on a single pan electronic balance. The weights of organs were expressed as $\mathrm{mg} / 100 \mathrm{~g}$ of body weight. ${ }^{[13]}$

\section{Sperm analysis}

The motility, viability and number of spermatozoa in the cauda epididymis were assessed in the present investigation. The animals were sacrificed by cervical dislocation and the cauda epididymis was transected at the point of origin of the vas deferens at the distal end and placed in a watch glass containing $0.5 \mathrm{ml}$ of normal saline $(0.9 \% \mathrm{NaCl})$ maintained at $37^{\circ} \mathrm{C}$. The tissue was minced carefully with the help of fine forceps and scissors to ensure the extrusion of spermatozoa. The tissue fractions were removed by using the fine forceps and a needle and the suspension was used for sperm analysis according to the WHO Laboratory Manual. ${ }^{[14,15]}$

\section{Sperm motility}

A drop of sperm suspension was placed on a clear glass slide and then covered with a cover slip. The slide was then examined under the microscope at 400X and the motility was scored in different fields of view. Spermatozoa showing any degree of movement were considered to be motile. All spermatozoa (motile as well as immotile) were counted with the help of a blood cell counter. Sperm motility was calculated using the following formula:

Motility $(\%)=$ number of motile spermatozoa / total number of spermatozoa (motile + immotile) $\times 100$

\section{Sperm viability}

Sperm viablity was assessed by using a supra-vital staining technique based on the principle that cells with damaged plasma membrane take up the stain, while viable ones do not. All glass wares as well as the eosinnigrosin stain were maintained at $37^{\circ} \mathrm{C}$. A drop of sperm suspension and a drop of eosin-nigrosin stain ( $1 \%$ eosin $+5 \%$ nigrosin, $1: 1)$ were placed on a clear glass slide and mixed thoroughly with the help of a fine glass rod. A portion of the mixture was transferred to a second slide and a thin film was prepared. The slide was then examined under the microscope (400X) and about one hundred spermatozoa (viable and dead) were counted from different fields of the slide. Spermatozoa appearing pinkish (stained) were considered to be dead, while those appearing colorless (unstained) were counted as viable.

Sperm viability was calculated in percent by using the following formula: Viability $(\%)=$ number of viable spermatozoa / total number of spermatozoa $($ viable + dead $) \times 100$.

\section{Sperm count}

A hemocytometer with improved Neubauer ruling was employed for counting the spermatozoa. A 20 -fold dilution was made by mixing the sperm suspension with normal saline $(0.9 \% \mathrm{NaCl})$. The preparation was then thoroughly mixed and one drop was added to both sides of the hemocytometer. The number of spermatozoa was counted in the four corner squares of the hemocytometer under a microscope at 400X. If spermatozoa crossed the lines of the grid, only those at the top and righthand sides of the squares were counted. Spermatozoa on both sides of the hemocytometer were counted and the average number was recorded. Number of spermatozoa per cauda epididymidis was expressed as follows:

Sperm number $=$ averaged no. of spermatozoa counted $(\mathrm{N}) \times$ multiplication factor $\left(10^{\prime} 000\right) \times$ dilution factor $(20)=\mathrm{N} \times 10^{\prime} 000 \times 20=$ $\mathrm{N} \times 0.2 \times 10^{6}$ spermatozoa. 


\section{Histological studies}

After 28 days of treatments to animals of all respective groups, testis of animals from each group was dissected out. The testis was fixed in Bouin's fluid for histological studies. Twenty-four hours after fixation, the tissues were dehydrated in an ascending series of alcohol, treated with xylene and embedded in paraffin wax. 6-mm-thick sections were cut by a rotary microtome (York Scientific Industries PVT. LTD, India) and stained with Hematoxylin and Eosin (H\&E). Histological sections of the testis were viewed in microscope and images were captured with a digital camera.

For determination of the percentage of affected seminiferous tubules, all the tubules in a randomly selected section of the testis from three rats of each group were counted. ${ }^{[16]}$ The seminiferous tubules were considered affected if they showed any of the following details: regenerated appearance of germ cells; condition of germinal epithelium; presence of spermatids of different stages of spermatogenic cycle in the same tubule; diameter of the seminiferous tubule; presence of spermatogonia; presence of primary and secondary spermatocytes; differentiation of spermatids; lumen of the seminiferous tubule; sertoli cell cytoplasm; presence of stages of spermatogenesis; formation of clones of germ cells, structure and distribution of Leydig cells.

\section{Serum total testosterone measurement}

On the $28^{\text {th }}$ day, blood was collected to measure serum testosterone level. Blood samples were spun at $2500 \mathrm{~g}$ for $10 \mathrm{~min}$ in a table top centrifuge. The serum samples obtained were analyzed to determine the concentration of testosterone. Serum concentration of total testosterone was measured by using a double antibody ELISA kit (Eiagen Testosterone kit, Italy). The protocol used for the testosterone determination was according to the method described for the kit. Serum concentrations of hormones were determined in triplicate samples. ${ }^{[17]}$

\section{Statistical analysis}

Results are expressed as mean \pm standard error mean (SEM). The groups were compared by ANOVA, followed by Dunnet's test. All the statistical analysis was carried out using Instate version, 2.1 software. Etholog 2.1 was used for computation of the behavioral parameters.

\section{RESULTS}

\section{Effect on body weight and weight of reproductive organs}

A significant decrease in body weights of lead acetate group animals was observed upon completion of experimentation on days 91. Similarly, the testicular weight was also reduced significantly in lead acetate intoxicated group animals. There was a significant recovery in body and testicular weights of animals in extract treated animals. The percent reduction in body weight of lead acetate intoxicated group animals was $10.6 \%$ while there was only $3.5 \%$ reduction of body weight in A. pyrethrum treated group, in $S$. acmella extract treated group the reduction was only $4.4 \%$ and in P. murex treated group it was $4.07 \%$. The result clearly demonstrated the effectiveness of extracts in preserving the loss of body weight in following order (Table 1 and Figure 1).

\section{A) pyrethrum $>$ P. murex $>$ S. acmella}

In case of testicular weights, a significant reduction was observed in lead acetate group animals. Treatment with extract of all the herbs was highly effective in ameliorating the damages caused by exposure to lead acetate. There was a remarkable reduction in testicular weight $(15.2 \%)$ in lead acetate intoxicated group animals. On treatment with $A$. pyrethrum, $S$.

\section{Table 1: Effect of ethanolic extract of A. pyrethrum, S. acmella and P. murex on body and sexual organ weights in lead acetate intoxicated male rats.}

\begin{tabular}{|c|c|c|c|c|c|c|}
\hline \multirow{2}{*}{$\begin{array}{l}\text { Group and } \\
\text { treatment }\end{array}$} & \multicolumn{2}{|c|}{$\begin{array}{l}\text { Body weight } \\
\text { of animals (g) }\end{array}$} & \multirow[t]{2}{*}{$\begin{array}{l}\text { Weight of testis } \\
\text { (mg /100 g b.w) }\end{array}$} & \multirow{2}{*}{$\begin{array}{c}\begin{array}{c}\text { Weight of } \\
\text { prostate }\end{array} \\
\text { (mg/100 g b.w.) } \\
\text { After } 2\end{array}$} & \multirow[t]{2}{*}{$\begin{array}{l}\text { Weight of seminal } \\
\text { vesicles } \\
\text { (mg / } 100 \text { g b.w.) }\end{array}$} & \multirow[t]{2}{*}{$\begin{array}{l}\text { Weight of epididymis } \\
\text { (mg /100 g b.w.) }\end{array}$} \\
\hline & 0 day & After 28 day & & & & \\
\hline Control & $160.5 \pm 10.11$ & $176.1 \pm 5.17^{\star *}$ & $710.1 \pm 12.1^{* *}$ & $162.3 \pm 9.2^{* *}$ & $592.6 \pm 5.1^{* *}$ & $715.3 \pm 21.2^{* *}$ \\
\hline LA & $157.1 \pm 8.7$ & $140.4 \pm 9.21$ & $602.1 \pm 9.7$ & $106.1 \pm 7.3$ & $501.3 \pm 11.1$ & $613.1 \pm 15.1$ \\
\hline $\mathrm{LA}+\mathrm{AP} 150$ & $152.5 \pm 9.5$ & $147.1 \pm 7.0^{\star \star}$ & $685.2 \pm 10.5^{* *}$ & $142.1 \pm 5.5^{\star *}$ & $581.9 \pm 14.2^{\star *}$ & $695.4 \pm 12.8^{* *}$ \\
\hline $\mathrm{LA}+\mathrm{SA} 150$ & $161.1 \pm 7.9$ & $154 \pm 8.05^{* *}$ & $675.1 \pm 12.2 * *$ & $132.3 \pm 6.4^{* *}$ & $576.1 \pm 10.06^{* *}$ & $673 \pm 11.49 * *$ \\
\hline $\mathrm{LA}+\mathrm{PM} 150$ & $156.9 \pm 10.2$ & $150.5 \pm 8.2^{* *}$ & $681.6 \pm 7.3 * *$ & $138.7 \pm 3.7 * *$ & $580.8 \pm 8.3^{* *}$ & $684.7 \pm 10.17^{* *}$ \\
\hline
\end{tabular}

Weight of testes, prostate, seminal vesicles is expressed as $\mathrm{mg} / 100 \mathrm{~g}$ body weight.

All values are expressed as mean \pm S.E.M, $n=6 ; P^{\star}<0.05$ and $P^{\star *}<0.01$ Considered significant as compared to control. Control: No drug;

LA: Lead acetate diluted in mineral water at $250 \mathrm{mg} / 1$ ( $1 \mathrm{ml}$ mineral water poisoned/day/ rat) for 90 days.

LA+AP 150: Lead acetate diluted in mineral water $250 \mathrm{mg} / \mathrm{l}(1 \mathrm{ml}$ mineral water poisoned/day/ rat $)+150 \mathrm{mg} / \mathrm{kg}$ body weight of ethanolic extract of A. pyrethrum, p.o., for 90 days.;

LA+SA150: Lead acetate diluted in mineral water $250 \mathrm{mg} / \mathrm{l}(1 \mathrm{ml}$ mineral water poisoned/day/ rat $)+150 \mathrm{mg} / \mathrm{kg}$ body weight of ethanolic extract of S. acmella in $1 \%$ sodium CMC solution, p.o., for 90 days;

LA+PM 150: Lead acetate diluted in mineral water $250 \mathrm{mg} / 1(1 \mathrm{ml}$ mineral water poisoned/day/ rat $)+150 \mathrm{mg} / \mathrm{kg}$ body weight of ethanolic extract of

P. murex in $1 \%$ sodium CMC solution, p.o., for 90 days 
acmella and $P$. murex extract reduction in testicular weight noted was $3.5,4.9$ and $4.0 \%$, respectively as compared to lead acetate intoxicated group animals. The weight of epididymis, seminal vesicles and prostate in all extract treated groups is either better or comparable with lead acetate intoxicated group animals (Table 1 and Figure 2).

\section{Effect on sperm parameter}

The effect of lead acetate exposure on total epididymal sperm count, sperm motility and sperm viability is shown in Table 2 and Figure 3. There was a significant reduction in sperm count in the testicular section of lead acetate intoxicated group animal as compared to extract treated animals. The observation in lead acetate group animals was $3.31 \times 10^{6} / \mathrm{ml}$. In contrast the sperm count in A. pyrethrum, S. acmella and P. murex extract treated group animals was $5.58 \times 10^{6}, 5.21 \times 10^{6}$ and $5.65 \times 10^{6} / \mathrm{ml}$, respectively (Figure 4). A significant decline in the levels of sperm motility and viability was also observed in rats exposed to lead for 90 days. Rats treated with lead acetate plus ethanolic extracts of A. pyrethrum, S. acmella and P. murex showed higher percentage for sperm motility and viability than the lead acetate intoxicated group animal.

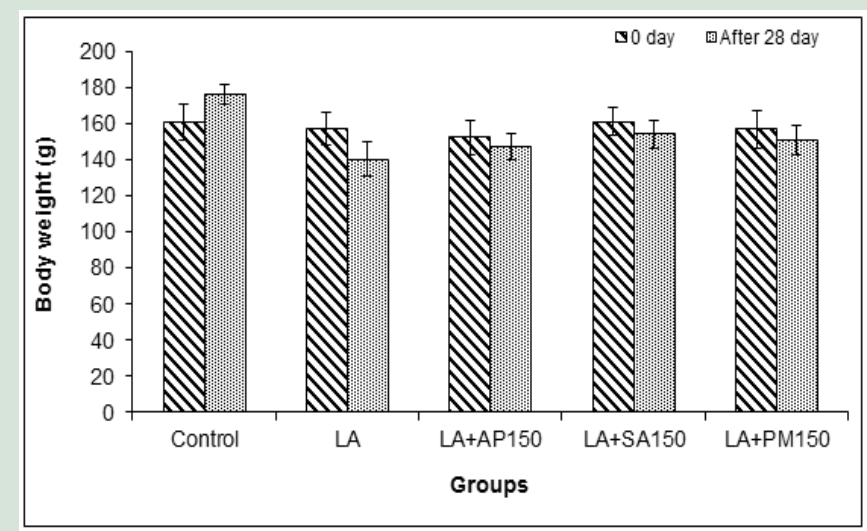

Figure 1: Effect of ethanolic extract of A. pyrethrum, S. acmella and $P$. murex on body weight in lead acetate intoxicated male rats.

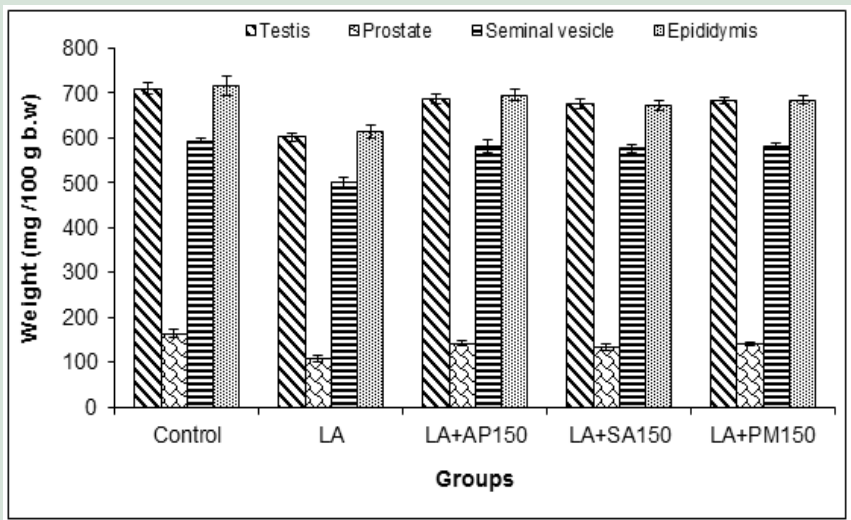

Figure 2: Effect of ethanolic extract of A. pyrethrum, S. acmella and $P$. murex on sexual organ weights in lead acetate intoxicated male rats.

\section{Effect on serum testosterone level}

A significant reduction occurred in the serum level of testosterone in rats exposed to lead as compared to control rats (Table 2 and Figure 5). The testosterone level of lead acetate intoxicated group was found to be $1.04 \pm 0.15(\mathrm{ng} / \mathrm{ml})$. The results indicate that serum testosterone level was restored in extract treated animals. The level of testosterone was observed $2.27 \pm 0.17,2.15 \pm 0.211$ and $2.09 \pm 0.16 \mathrm{ng} / \mathrm{ml}$ in A. pyrethrum, $S$. acmella and $P$. murex treated animals, respectively.

\section{Effect on testes histomorpholgy}

The sections of testes from control rats showed the normal structure of the testis. The seminiferous tubules appeared rounded or oval in their outlines and lined by germinal epithelium showing two types of cells; germ cells and Sertoli cells (Photograph 1a). Sertoli cells were detected in between spermatogenic cells as pyramidal cells with pale basal oval or triangular nuclei and prominent nucleoli. The spermatogenic cells were seen in regularly arranged rows with different stages of spermatogenesis. They were arranged from the basal compartment to the lumen of the tubules starting from spermatogonia (type A and B), primary spermatocytes, rounded and elongated spermatids till mature spermatozoa in the lumen. The seminiferous tubules were surrounded

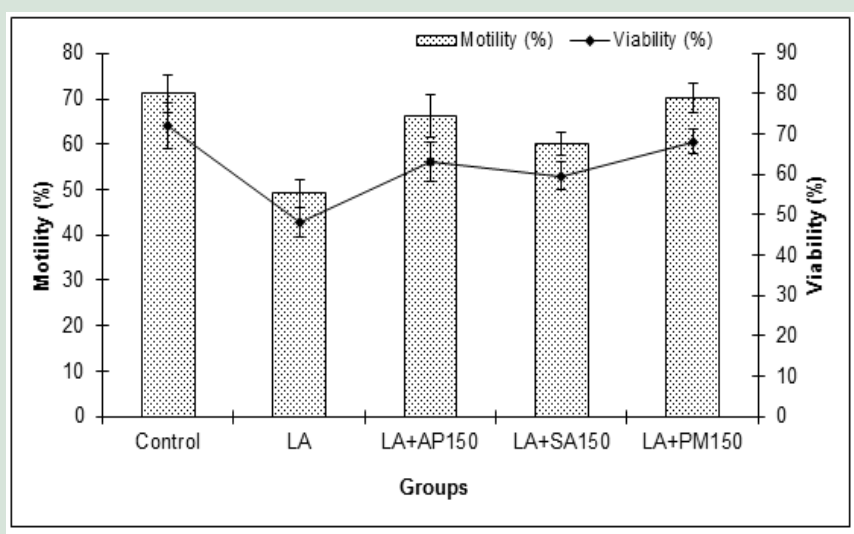

Figure 3: Effect of administration of ethanolic extract of $A$. pyrethrum, S. acmella and $P$. murex on male rat's sperm motility and viability in lead acetate intoxicated male rats

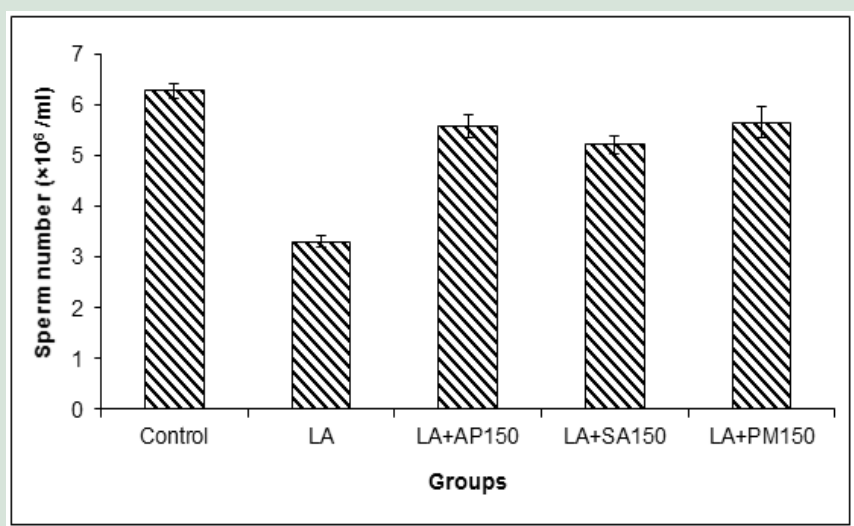

Figure 4: Effect of administration of ethanolic extract of A. pyrethrum, $S$. acmella and $P$. murex on sperm count in lead acetate intoxicated male rats 


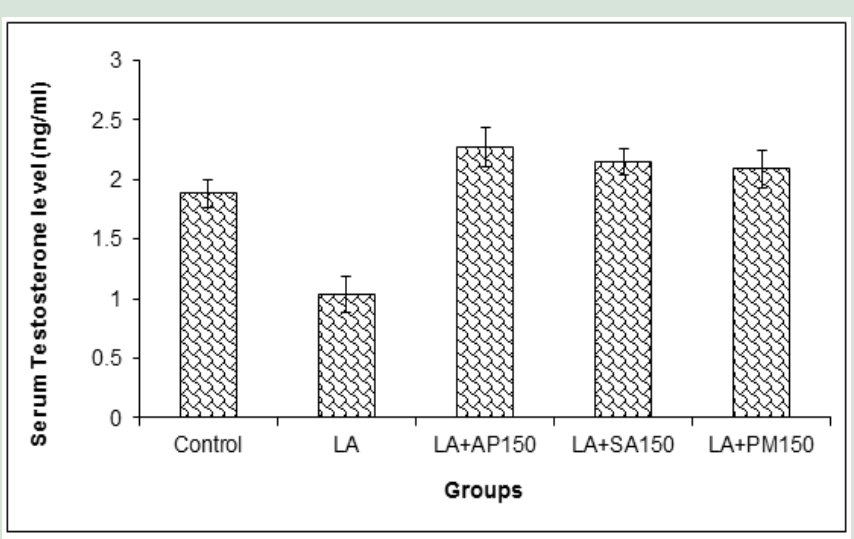

Figure 5: Effect of administration of ethanolic extract of $A$. pyrethrum, $S$. acmella and $P$. murex on serum testosterone level in lead acetate intoxicated male rats.

by a thin connective tissue layer with myoid cells. The other control subgroups showed similar histological characters.

Examination of sections obtained from testes of lead intoxicated rats revealed seminiferous tubules with vacuolations in the spermatogenic epithelium mostly separating primary spermatocytes from spermatogonia and surrounding nuclei of Sertoli cells (Photograph $1 \mathrm{~b}$ ). Testes of few animals showed some thin walled seminiferous tubules with wide lumen and vacuolations in the basal part of the spermatogenic epithelium with decreased number of germ cells. Apoptotic bodies were found within the basal part of the spermatogenic epithelium. Focal thickening of the connective tissue bounding the tubules was noticed in some tubules. Some spermatogonia appeared shrunken with pyknotic nuclei.

Animals that received lead together with ethanolic extract of $A$. pyrethrum, S. acmella and $P$. murex showed wide areas of testicular tissue similar to the examined control sections. However, focal areas of basal vacuolations in the germinal epithelium were noticed only in limited tubules (Photograph $1 \mathrm{c}, \mathrm{d}$ and e).

It is noteworthy that all the three herbal extracts are helpful in preventing the testicular damage caused by lead acetate and preserve the testicular integrity. The most effective treatment in the experiment was with $A$. pyrethrum extract, the others following closely.

\section{DISCUSSION}

It was demonstrated that intratesticular testosterone levels are decreased in rats treated with lead acetate; ${ }^{[18]}$ therefore we suggest that decreased spermatogenesis were caused by a reduction in intra-testicular testosterone levels. Supporting this hypothesis, other researchers concluded that lead alters sperm function by altering the hormonal control of spermatogenesis rather than by direct toxic action on spermatozoa. ${ }^{[19]}$ Ethanolic extracts of selected herbs was able to bring back serum testosterone levels suggesting that herbs may affect sperm count through a mechanism related to testosterone levels.

Many studies indicate that heavy metals act as catalysts in the oxidative reactions of biological macromolecules therefore the toxicities with these metals might be due to oxidative tissue damage; ${ }^{[20-22]}$ Cuypers et al. 1999; ${ }^{[23]}$ Leonard et al. 2004; ${ }^{[24]}$ Flora et al. 2008). ${ }^{[25]}$ Redox-active metals, such as iron $(\mathrm{Fe}), \mathrm{Cu}$ and chromium $(\mathrm{Cr})$, undergo redox cycling whereas redox-inactive metals, such as $\mathrm{Pb}, \mathrm{Cd}, \mathrm{Hg}$ and others deplete cells' major antioxidants, particularly thiol-containing antioxidants and enzymes. Either redox-active or redox-inactive metals may cause an increase in production of ROS such as hydroxyl radical ( $\left.\mathrm{HO}^{-}\right)$, superoxide radical

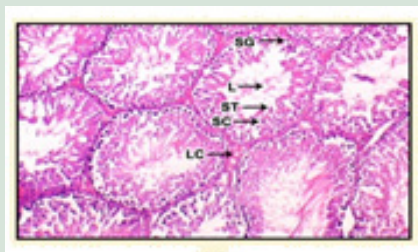

(a)

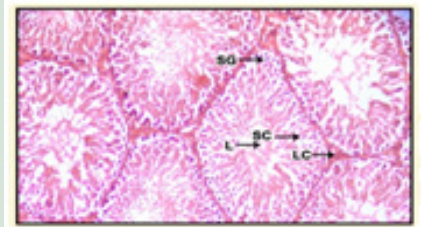

(c)

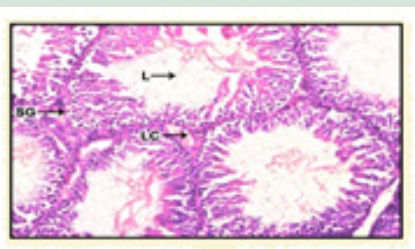

(b)

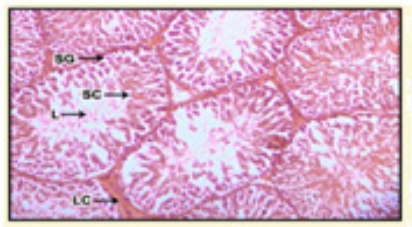

(d)

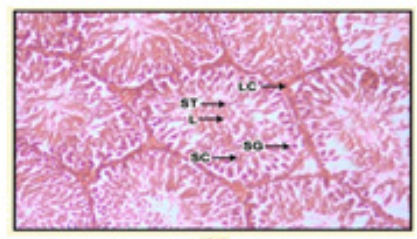

(c)

Photograph 1: Histopathological observations of the effect of different ethanolic extracts in lead acetate induced testis toxicity in male rats. L indicates Lumen of seminiferous tubules, LC indicates the Leydig cells and arrows of SG, SC and ST indicates spermatogonia, Spermatocytes and Spermatids. (a) Control (b) LA (c) LA+AP150 (d) LA+SA 150 (e) LA+PM150

$\left(\mathrm{O}^{-2}\right)$ or hydrogen peroxide $\left(\mathrm{H}_{2} \mathrm{O}_{2}\right)$. Enhanced generation of ROS can overwhelm cells' intrinsic antioxidant defenses and result in a condition known as "oxidative stress". Cells under oxidative stress display various dysfunctions due to lesions caused by ROS to lipids, proteins and DNA. Consequently, it is suggested that metal-induced oxidative stress in cells can be partially responsible for the toxic effects of heavy metals. ${ }^{[26]}$ In recent research literature the effect of antioxidant supplementation followed heavy metals exposure was reported. They suggest that antioxidants may play an important role in abating some health hazards of heavy metals in connection with an interaction of physiological free radicals (health effects). So, multiple mechanisms may be responsible for ROS production in toxic metal exposure. Among them, duction of ROS and damage to cell's antioxidant defense systems are well known for all redox-active and inactive elements. ${ }^{[27]}$

From the present results, it is obvious that treating heavy metalsintoxicated rats with all selected ethanolic extracts significantly protected the testis structures and functions as compared to the lead intoxicated group. Ethanolic extracts of selected herbs allows free radicals to abstract a hydrogen atom from the antioxidant molecule rather than from polyunsaturated fatty acids, thus breaking the chain of free radical reactions, the resulting antioxidant radicals being a relatively unreactive species. ${ }^{[28,29]}$

Therefore ethanolic extracts of all selected herbs are sufficient to protect the organism from toxic agent and free radical damage. It has been reported that reactive oxygen species, generated in vitro, can cause DNA fragmentation in human sperm, but that this could be prevented by preincubation with antioxidants.

Previous phytochemical investigations have shown the presence of phenolic compounds such as flavonoids, flavonol and quercetin in selected herbs. In fact, all selected herbs have been demonstrated to have antioxidant properties in vitro and in vivo. For instance, lead acetate administration causes an increase in oxidative status and it has 
Sharma, et al.: Protective Effect of Ayurvedic Rasayana Herbs in Reproductive Health

Table 2: Effect of administration of ethanolic extract of $A$. pyrethrum, S. acmella and $P$. murex on male rats sperm motility, viability and number of spermatozoa in cauda epididymidis ,Fructose content in seminal vesicle and serum Testosterone level in lead acetate intoxicated male rats.

\begin{tabular}{|c|c|c|c|c|}
\hline Group and treatment & Motility (\%) & Viability (\%) & $\begin{array}{c}\text { Sperm number } \\
\left(\times 10^{6} / \mathrm{ml}\right)\end{array}$ & $\begin{array}{c}\text { Testosterone level } \\
(\mathrm{ng} / \mathrm{ml})\end{array}$ \\
\hline Control & $71.12 \pm 4.03^{* *}$ & $72.12 \pm 5.81^{* *}$ & $6.28 \pm 0.15^{* *}$ & $1.88 \pm 0.12^{* *}$ \\
\hline LA & $49.22 \pm 3.10$ & $48.12 \pm 3.71$ & $3.31 \pm 0.11$ & $1.04 \pm 0.15$ \\
\hline LA + AP150 & $66.31 \pm 4.72^{* *}$ & $63.20 \pm 4.90^{* *}$ & $5.58 \pm 0.21^{* *}$ & $2.27 \pm 0.17^{*}$ \\
\hline LA + SA150 & $60.14 \pm 2.40^{* *}$ & $59.60 \pm 3.41^{* *}$ & $5.21 \pm 0.19^{* *}$ & $2.15 \pm 0.11^{* *}$ \\
\hline LA + PM150 & $70.10 \pm 3.18^{* *}$ & $68.18 \pm 2.87^{* *}$ & $5.65 \pm 0.31^{* *}$ & $2.09 \pm 0.16^{* *}$ \\
\hline
\end{tabular}

All values are expressed as mean \pm S.E.M, $n=6 ; P^{\star}<0.05$ and $P^{\star *}<0.01$ Considered significant as compared to control.

Control: No drug;

LA: Lead acetate diluted in mineral water at $250 \mathrm{mg} / 1$ ( $1 \mathrm{ml}$ mineral water poisoned/day/ rat) for 90 days.

LA+AP 150: Lead acetate diluted in mineral water $250 \mathrm{mg} / \mathrm{l}(1 \mathrm{ml}$ mineral water poisoned/day/ rat $)+150 \mathrm{mg} / \mathrm{kg}$ body weight of ethanolic extract of A. pyrethrum, p.o., for 90 days.;

LA+SA150: Lead acetate diluted in mineral water $250 \mathrm{mg} / 1$ ( $1 \mathrm{ml}$ mineral water poisoned/day/ rat $)+150 \mathrm{mg} / \mathrm{kg}$ body weight of ethanolic extract of

S. acmella in $1 \%$ sodium CMC solution, p.o., for 90 days;

LA+PM 150: Lead acetate diluted in mineral water $250 \mathrm{mg} / 1$ ( $1 \mathrm{ml}$ mineral water poisoned/day/ rat $)+150 \mathrm{mg} / \mathrm{kg}$ body weight of ethanolic extract of

P. murex in $1 \%$ sodium CMC solution, p.o., for 90 days

been shown in male rats to reduce spermatogenesis and epididymal sperm count; Ethanolic extracts reversed this effect. Thus, ethanolic extract of selected herbs could play a role in regulating sperm number by maintaining the balance between oxidant and antioxidant status. In addition, it has been demonstrated that these constituents have potent scavenging activity. Again, other investigators found a high total phenolic content an ethanolic extracts, supporting the hypothesis that the effect observed on sperm production might be related to these compounds and their antioxidant activity.

Vajikarana therapy improves the function of the reproductive organs and vitalizes reproductive tissues, increasing sperm count and strengthening their motility and viability. While some Vajikarana herbs work as aphrodisiacs, they also engender reproductive strength. Vajikarana not only enhances the quality and longevity of individual life, but also treats infertility by nourishing the whole body as well as the reproductive tissues and sexual fluids.

\section{ACKNOWLEDGEMENT}

Funding by the All India Council, New Delhi, India for technical education in the form of National Doctoral Fellowship is duly acknowledged.

\section{CONFLICT OF INTEREST}

The authors declare no conflict of interest.

\section{REFERENCES}

1. Benoff S, Jacob A, Hurley IR. Male infertility and environmental exposure to lead and cadmium. Hum Reprod Update. 2000;6(2):107-21.

2. Benoff S, Centola GM, Millan C, Napolitano B, Marmar JL, Hurley IR. Increased seminal plasma lead levels adversely affect the fertility potential of sperm in IVF Hum Reprod. 2003;18(2):374-83.

3. Wong WY, Thomas CMG, Merkus JMWM, Zielhuis GA, Steegers-Theunissen RPM. Male factor subfertility: Possible causes and the impact of nutritional factor. Fertil Steril. 2000;73(3):435-42

4. Sokol RZ. Hormonal effects of lead acetate in the male rat: Mechanism of action. Biol Reprod. 1987;37(5):1135-8.
5. Dorostghoal M, Dezfoolian A, Sorooshnia F. Effects of maternal lead acetate exposure during lactation on postnatal development of testis in offspring wistar rats Iran J Basic Med Sci. 2011;14(2):122-31.

6. Chauhan NS, Sharma V, Dixit VK, Thakur M. A Review on Plants Used for Improvement of Sexual Performance and Virility. Bio Med Research International. 2014;1-19.

7. Sharma V, Thakur M, Chauhan NS, Dixit VK. Effect of petroleum ether extract of Anacyclus pyrethrum DC on sexual behaviour in male rats. J Chin Integr Med. 2010;8(8):767-73

8. Sharma V, Boonen J, Chauhan NS, Thakur M, DeSpiegeleer B, Dixit VK. Spilanthes acmella ethanolic flower extract: LC-MS alkylamide profiling and its effects on sexual behavior in male rats. Phytomedicine. 2011;18(13):1161-9.

9. Sharma $V$, Thakur M, Dixit VK. A comparative study of ethanolic extracts of Pedalium murex Linn. fruits and sildenafil citrate on sexual behaviors and serum testosterone level inmale rats during and after treatment. Journal of Ethnopharmacology. 2012;143(1):201-6.

10. Sharma V, Boonen J, Spiegeleer BD, Dixit VK. Androgenic and spermatogenic activity of alkylamide-rich ethanol solution extract of Anacyclus pyrethrum DC Phytotherapy Research. 2013;27(1):99-106.

11. Rubio J, Riqueros MI, Gasco M, Yucra S, Miranda S, Gonzales GF. Lepidium meyenii (Maca) reversed the lead acetate induced-damage on reproductive function in male rats. Food Chem Toxicol. 2006;44(7):1114-22.

12. Allouchea L, Hamadouche M, Touabti A. Chronic effects of low lead levels on sperm quality, gonadotropins and testosterone in albino rats. Exp Toxicol Pathol. 2009;61 (5):503-10.

13. Thakur M, Dixit VK. Effect of Chlorophytum borivilianum on androgenic and sexual behavior of male rats. Ind Drugs. 2006;43(4):300-6.

14. World Health Organization. WHO Laboratory Manual for the Examination of Human Semen and Semen-Cervical Mucus Interaction. Cambridge University Press: Cambridge.1999.

15. Sethi S, Chaturvedi $\mathrm{CM}$. Temporal synergism of neurotransmitters (serotonin and dopamine) affects testicular development in mice. Zoology. 2009;112(6):461-70.

16. Singh SK, Chakravarty S. Antispermatogenic and antifertility effect of 20, 25-diazacholesterol dihydrochloride in mice. Reprod Toxicol. 2003;17(1):37-44.

17. Chauhan NS, Dixit VK. Effects of Bryonia laciniosa seeds on sexual behaviour of male rats. Int J Impot Res. 2010;22(3):190-5.

18. Sokol RZ, Madding CE, Swerdloff RS. Lead toxicity and the hypothalamic-pituitary-testicular axis. Biol Reprod. 1985;33(3):722-8.

19. Sokol RZ, Okuda H, Nagler HM, Berman N. Lead exposure in vivo alters the fertility potential of sperm in vitro. Toxicol Appl Pharmacol. 1994:124(2):310-6.

20. Stohs SJ, Bagchi D. Oxidative mechanisms in the toxicity of metals ions. Free Radic Biol Med. 1993;18(2):321-36.

21. Hultberg $B$, Andersson $A$, Isaksson $A$. Thiol and redox reactive agents exert 
different effects on glutathione metabolism in Hela cell culture. Clin Chim Acta. $1999 ; 283(1-2): 21-32$.

22. Hultberg $B$, Andersson A, Isaksson A. Interaction of metals and thiol in cell damage and glutathione distribution: Potentiation of mercury toxicity by dithiothreitol. Toxicol. 2001;156(2-3):93-100.

23. Cuypers A, Vangronsveld J, Clijsters $H$. The chemical behaviors of heavy metals play a prominent role in the induction of oxidative stress. Free Radic Res. 1999;31(Suppl):39-43

24. Leonard SS, Harris GK, Shi XL. Metal-induced oxidative stress and signal transduction. Free Radic Biol Med. 2004;37(12):1921-42.

25. Flora SJS, Mittal M, Mehta A. Heavy metal induced oxidative stress and its possible reversal by chelation therapy. Indian J Med Res. 2008;128(4):501-23

\section{GRAPHICAL ABSTRACT}

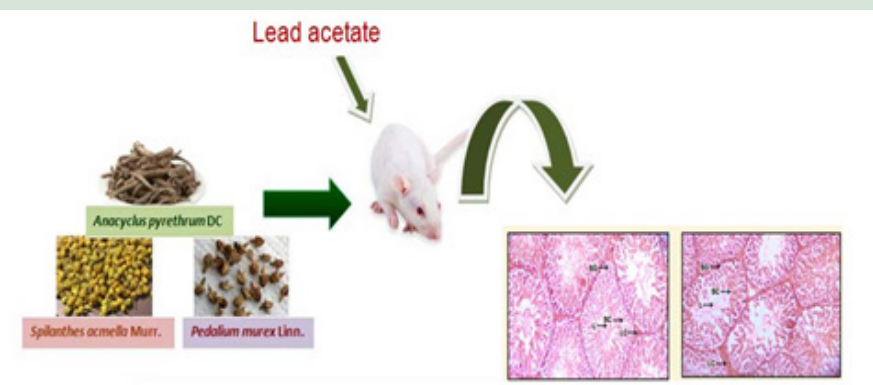

Protective effect of Vajikran Rasayana on lead acetate-induced testicular toxicity
26. Ercal N, Gurer-Orhan H, Aykin-Burns N. Toxic metals and oxidative stress Part 1 mechanisms involved in metal induced oxidative damage. Curr Top Med Chem. 2001;1(6):529-39

27. Kaminski P, Kurhalyuk N, Szady-Grad M. Heavy metal induced oxidative stress and changes in physiological process of free radicals in the blood of White Stork (Ciconia ciconia) chicks in polluted areas. Pol J Environ Stud. 2007;16:555-62.

28. Pascoe G, Olafsdottier F, Read D. Vitamin E protection against chemical-induced cell injury. I. Maintenance of cellular protein thiols as a cytoprotective mechanism. Arch Biochem Biophys. 1987;256(1):150-8.

29. Al-Attar AM. Antioxidant effect of vitamin E treatment on some heavy metals-induced renal and testicular injuries in male mice. Saudi J Biol Sci. 2011;18(1):6372.

\section{SUMMARY}

In recent years, the use of the herbs in reducing heavy metal toxicities has increased worldwide. Rasayana drugs have been reported to have improved reproductive activity. The male rats were given daily with lead acetate and Anacyclus pyrethrum, Spilanthes acmella and Pedalium murex BW orally once in day for 90 days. Results showed that Lead acetate decreased the sperm count, motility, viability, and altered histopathological testis compared to the negative control. On the other hand, administration of Rasayana drugs significantly improved the histopathological in testis, increased the sperm count, motility, viability, and also significantly increased the testosterone level in drug treated rats. From the results of this study we concluded that the studied Rasayana drugs are potent natural products in providing a promising protective effect against lead acetate induced testicular toxicity in rats.

\section{ABOUT AUTHORS}

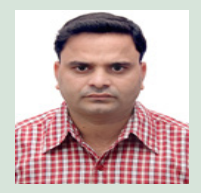

Dr.Vikas Sharma has more than 14 years of teaching and research experience. He has made significant contributions in the area of medicinal plant research. He has been working on evidence-based validation of medicinal plants and pharmacological screening of herbal drugs. Dr. Sharma works on marker and biomarker analysis of herbs for quality evaluation. He has also made significant contributions to development of chemical profiling of extracts and formulation through TLC, HPTLC and LC-MS. He is supervising scientific research of the post-graduation and the doctoral level. He has written several researches and review paper in reputed journals and has contributed several chapters in books on pharmaceutical and indigenous drugs. He is a member of various professional and academic bodies.

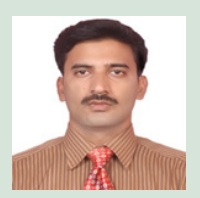

Dr. Nagendra Singh Chauhan has around 15 years of research experience. He is presently working as Senior Scientific Officer Grade-II and Government Analyst at Drugs Testing Laboratory Avam Anusandhan Kendra ,Raipur, Chhattisgarh, India. He has written more than 65 articles published in national and international journals, 24 book chapters and edited four books in publishers like Academic Press, CRC and Willey. He is a member of various professional and academic bodies like Society of Pharmacognosy India, International Natural Product Sciences Taskforce (INPST) society, SILAE: Società Italo-Latinoamericana di Etnomedicina (The Scientific Network on Ethnomedicine, Italy), Institutional Human ethical committee, Association of Pharmaceutical Teachers of India (APTI).

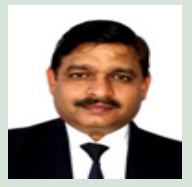

Dr. Umesh K. Patil is presently working as Professor of Pharmacognosy at Department of Pharmaceutical Sciences, Dr. Harisingh Gour Vishwavidyalaya (A Central University), Sagar. His research interest includes Herbal Drug Technology, Ethnopharmacology and Natural Products. He has more than 22 years of experience in teaching and research. He is recipient of 7 prestigious awards given in the field of HMPs and remained BOYSCAST fellow of DST, Govt of India.

Dr. Vinod Kumar Dixit has worked in academic and administrative capacities for more than 30 years and retired from active services as Professor of Pharmacognosy at Department of Pharmaceutical Sciences, Dr. Harisingh Gour Vishwavidyalaya (A Central University), Sagar. He has more than 40 years of experience in teaching and research. His research interest includes Standardization of Herbal Products, Herbal Drug Technology, Ethnopharmacology and Natural Product Research. He has served as General Secretary, Vice president, President of Indian Society of Pharmacognosy (ISP) and currently contributing to the society as one of the National Advisors of ISP.

History: Submission Date: 07-12-2020; Review Completed: 08-01-2021; Accepted Date: 31-01-2021

Cite this article: Sharma V, Chauhan NS, Patil UK, Dixit VK. Protective Effect of Rasayana Herbs on Lead Acetate-induced Testicular Toxicity in Wistar Rats. Indian J Nat Prod. 2021;35(1):9-15. 